\title{
MHC polymorphism and disease-resistance to Edwardsiella tarda in six turbot (Scophthalmus maximus) families
}

\author{
DU Min ${ }^{1,2,3}$, CHEN SongLin $^{1 *}$, LIU YanHong ${ }^{2}$, NIU BaoZhen ${ }^{2}$, YANG JingFeng ${ }^{1} \&$ \\ ZHANG Bo ${ }^{1}$ \\ ${ }^{1}$ Key Laboratory for Sustainable Utilization of Marine Fisheries Resources, Ministry of Agriculture, Yellow Sea Fisheries Research Institute, \\ Chinese Academy of Fishery Sciences, Qingdao 266071, China; \\ ${ }^{2}$ College of Life Sicence and Technology, Honghe University, Mengzi 661100, China; \\ ${ }^{3}$ College of Aqua-Life Science and Technology, Shanghai Ocean University, Shanghai 200090, China
}

Received October 19, 2011; accepted March 20, 2012; published online May 1, 2012

\begin{abstract}
This study examined genetic variation in the major histocompatibility complex (MHC) Class II B gene in turbot (Scophthalmus maximus) by virulent bacterial pathogen challenge. One hundred fry from each of six families were infected with Edwardsiella tarda by intraperitoneal injection. Family mortality ranged from $28.0 \%$ to $83.3 \%$. Complete exon 2 and intron 1 sequences of MHC Class II B genes were amplified from five survivor and five non-survivor individuals per family using the clone-sequence method. Thirty-seven sequences from 60 individuals revealed 37 different alleles, 25 of which were unique to this study. The 25 unique alleles belonged to 16 major allele types. Nine alleles were used to examine the association between alleles and resistance/susceptibility to disease. Five alleles were present in an individual, suggesting a minimum of three loci or copies of the turbot MHC Class II B gene. The rate of non-synonymous substitution $\left(d_{\mathrm{N}}\right)$ was 2.30 and 1.58 times higher than synonymous substitution $\left(d_{\mathrm{S}}\right)$ in the peptide-binding regions (PBR) and non-PBR in whole families, respectively, which suggested balancing selection on exon 2 of the MHC Class II B gene in turbot. One allele, Scma-DBB1*02, was significantly more prevalent in survivor stock than in non-survivor stock $(P=0.001)$. Therefore, this allele might be associated with resistance to bacteria. A second allele, $S c m a-D B B 1 * 10$, was significantly more prevalent in non-survivor stock $(P=0.021)$, and is likely associated with susceptibility to bacteria.
\end{abstract}

turbot (Scophthalmus maximus), Edwardsiella tarda, major histocompatibility complex II B, polymorphism, resistance, susceptibility

Citation: Du M, Chen S L, Liu Y H, et al. MHC polymorphism and disease-resistance to Edwardsiella tarda in six turbot (Scophthalmus maximus) families. Chin Sci Bull, 2012, 57: 3262-3269, doi: 10.1007/s11434-012-5179-y

The major histocompatibility complex (MHC) is a multigene family that plays a central role in the adaptive immune system. The MHC family includes two major subfamilies, termed Class I and Class II genes. Classical Class I and Class II MHC genes are heterodimeric, highly polymorphic, and encode cell-surface proteins that present antigenic self and non-self peptides to the T-cell receptor (TCR), initiating a cascade of complex immune responses [1,2]. Classical MHC Class I molecules contain an $\alpha$ and a $\beta_{2}$-microglobulin

*Corresponding author (email: chensl@ysfri.ac.cn) chain and are expressed on the surface of all nucleated somatic cells, while classical MHC Class II molecules contain one $\alpha$ and one $\beta$ chain, and are constitutively expressed on antigen-presenting cells of the immune system [3].

Following the identification of carp (Cyprinus carpio L.) [4] MHC gene fragments two decades ago, MHC Class I, Class II A and Class II B genes have been isolated and characterized in a large variety of fish species, including rainbow trout [5], Atlantic salmon [6], zebrafish [7], cichlid fish [8,9], carp [4,10], nurse-shark [11], cartilaginous fish [12], turbot [13], Japanese flounder [14,15], red sea bream 
[16], and half-smooth tongue sole [17]. Surprisingly, MHC classes I and II genes are found on the same linkage groups in all studied mammals, while in teleosts the MHC Class II genes were not linked with MHC Class I genes [18-24].

The presence of multiple loci and a considerable number of alleles at each given locus within populations has meant that classical MHC genes are the most polymorphic genes studied to date [25]. Extensive variability of MHC Class II $\mathrm{B}$ genes was discovered in the $\beta 1$ domain (exon 2), which encodes the functional peptide binding region (PBR) $[17,26]$. Allelic diversity is critical for resistance to a variety of parasites [27]. Several selective mechanisms have been proposed to elucidate the high level of polymorphism of the MHC genes, including parasite resistance, maternal-fetal interaction, negative-assortative mating, overdominant selection, heterozygous advantage, and frequency-dependent balancing selection [28,29]. However, the significance of the generation of new variants is still unknown.

Turbot (Scophthalmus maximus) is one of the most widely cultured marine fish species [13,30], and Edwardsiella tar$d a$ is one of the most significant pathogens affecting turbot farming [31]. The use of antibiotics in farmed fish is strictly controlled, but antibiotic residues may be harmful to human health and also have adverse effects on the environment. Selective breeding, especially gene-assisted selection of turbot for disease-resistant lines/families, is a promising solution [30,32]. Family members with a known genetic background were used for selective breeding because of their clear background information. In recent years, much research has gone into the molecular cloning, expression, and polymorphism analysis of turbot MHC II A and B genes [13]. Xu et al. [30] identified two alleles associated with susceptibility to $E$. tarda, with another allele associated with resistance in turbot populations.

This study aimed to estimate the number of MHC Class II loci in turbot, ascertain the extent of MHC molecular polymorphism, test for balancing selection in PBR, and identify any $\mathrm{MHC}$ alleles associated with variation in resistance or susceptibility to $E$. tarda in turbot families.

\section{Materials and methods}

\subsection{Fish families and rearing}

The six full-sibling families of turbot assessed in this study were established from six sires and six dams, as described previously $[32,33]$. These parents were reared and mated at the Aqua-Breeding Station (LaiZhou MinBo aquatic CO., Ltd.) in Laizhou, located in the north of Shandong Province, China. The parentage of the sires and dams was unknown, although it was assumed that they were unrelated. Following mating, fertilized eggs from each family were incubated, hatched in a separate tank from August 1-8 of 2009, and reared at the same breeding station in Laizhou. Fry were fed Brachionus plicatilis, brine shrimp, and a commercial compound feed using a routine feeding formula.

\subsection{Challenge experiments}

Approximately 600 fish were used in this study. Random samples of 100 fish from each family were divided into two replicate batches of approximately 50 individuals. Fry were allocated a separate tank with fresh seawater supply at $(21 \pm 0.5)^{\circ} \mathrm{C}$ under flow-through status. Prior to challenge, fish were fed a routine daily diet, while post challenge they were fed according to appetite. A pre-challenge experiment to estimate the median lethal bacterial concentration was performed using similarly sized fish (mean weight $18.2 \mathrm{~g}$, mean body length $10.2 \mathrm{~cm}$ ). For the challenge test in turbot, 50 fish from each family were inoculated by intraperitoneal (i.p.) injection of $0.2 \mathrm{~mL}$ E. tarda bacterial suspension $(\sim 1.4 \times$ $10^{7} \mathrm{CFU}$ /individual) according to the method of Zhang et al. [13]. As a control, 14 fish were injected with $0.2 \mathrm{~mL} 0.9 \%$ saline solution [15,25]. One individual per control group died during the test period. The challenge trial began on November 6, 2009 and lasted for $32 \mathrm{~d}$. Dead fish were collected from each tank daily and the number was recorded during the challenge period. Surviving fish were counted at the termination of the challenge trial and fin tissues from all trial fish were preserved individually in $100 \%$ ethanol.

\subsection{Sampling and DNA isolation}

Groups of dead and live fish from each family were selected for further analysis following the bacterial challenge (Table 1). Genomic DNA was extracted from the fin samples of both the first five fish to die and the last five survivors of each family, using a modified phenol-chloroform method, as described previously [15,34].

\subsection{Primer design and polymerase chain reaction (PCR) amplification}

A pair of gene specific primers, TPMHCIIBN1 (5'-CGCCCTCCTCTTCATCACTGT-3') and TPMHCIIBC1 (5'-TCA-

Table 1 Numbers of dead and surviving individuals selected from six families of turbot

\begin{tabular}{lccc}
\hline \multirow{2}{*}{ Family } & \multicolumn{2}{c}{ Individuals per family } & \multirow{2}{*}{ Total } \\
\cline { 2 - 3 } & Dead & Surviving & \\
\hline Family 1 & 5 & 5 & 10 \\
Family 2 & 5 & 5 & 10 \\
Family 3 & 5 & 5 & 10 \\
Family 5 & 5 & 5 & 10 \\
Family 6 & 5 & 5 & 10 \\
Family 7 & 5 & 5 & 10 \\
Total & 30 & 30 & 60 \\
\hline
\end{tabular}


GAGCAGCTTCATGGTCATTTC-3'), was designed based on known turbot MHC II B cDNA sequences [13]. The primers were used to amplify a fragment of the turbot MHC II B gene containing part of exon 1 and all of intron 1 and exon 2. Reactions contained approximately $100 \mathrm{ng}$ of template DNA, 1× Taq polymerase buffer (TransGen Biotech, Beijing, China), $1.5 \mathrm{mmol} \mathrm{L}^{-1} \mathrm{MgCl}_{2}, 0.2 \mathrm{mmol} \mathrm{L}^{-1}$ deoxynucleotide triphosphate, $0.2 \mu \mathrm{mol} \mathrm{L} \mathrm{L}^{-1}$ of the forward and reverse primers, and $1 \mathrm{U}$ of Taq polymerase (TransGen Biotech). Cycling conditions were as follows: $5 \mathrm{~min}$ at $94^{\circ} \mathrm{C}$, followed by 30 cycles of $94^{\circ} \mathrm{C}$ for $40 \mathrm{~s}, 53^{\circ} \mathrm{C}$ for $40 \mathrm{~s}$, and $72^{\circ} \mathrm{C}$ for $50 \mathrm{~s}$, and a final extension of $10 \mathrm{~min}$ at $72^{\circ} \mathrm{C}$. PCR reactions were performed on a Peltier Thermal Cycler (PTC-200). PCR products were visualized by electrophoresis on a $1 \%$ agarose gel and imaging on a Molecular Imager Gel Doc XR system (BioRad, Hercules, CA, USA).

\subsection{Cloning and sequencing}

PCR products were electrophoresed on $1.5 \%$ agarose gels and the expected amplified fragments were excised before being purified with a QIAEX II gel extraction kit (Qiagen, Hilden, Germany). PCR amplicons were cloned into the PBS-T vector (Takara Bio, Otsu, Japan) and propagated in TOP 10 Escherichia coli competent cells (TransGen Biotech) following manufacturer's instructions. Vector specific sequencing primers M13 (5'-CGCCAGGGTTTTCCCAGTCACGAC- $3^{\prime}$ ) and RV-M (5'-AGCGGATAACAATTTCACACAGG-3'), were used to confirm positive clones by PCR. Five positive clones from each individual were sequenced using an ABI 3730 automated sequencer (Applied Biosystems, Foster City, CA, USA).

\subsection{Amino acid sequence analysis and statistical tests}

All sequences were aligned using ClustalW [35]. The rate of non-synonymous substitution $\left(d_{\mathrm{N}}\right)$ and synonymous substitution $\left(d_{\mathrm{S}}\right)$ in the putative PBR and non-PBR was determined using MEGA version 4.0 [36], employing the Nei and Gojobori method with $p$-distance [37]. Statistical analyses were carried out using SPSS 13.0 (IBM, Armonk, NY, USA) and polymorphic value analysis was performed using DnaSP 4.0 [38].

Novel alleles, as determined by the deduced amino acid sequences, were designated Scma-DAB*0101-Scma-DAB* 1601 according to the rules proposed by Davies et al. [39]. The abbreviation Scma refers to Scophthalmus maximus, D to Class II, A to uncharacterized family designation, and B to the $\beta$ chain-encoding genes. In the four digits following an asterisk, the first two digits refer to the major type (alleles that differ by at least five amino acid substitutions), and the next two digits to the subtype (alleles that differ by less than five amino acid substitutions within a single major type) $[15,40]$.

\section{Results}

\subsection{Disease resistance/susceptibility comparison of six turbot families}

All individuals from six full-sibling families were i.p. injected with a bacterial suspension of approximately $2.8 \times 10^{6}$ CFU of E. tarda. The average mortality rate was $72.5 \%$, with the within-family mortality rate ranging from $66.1 \%-83.3 \%$. The mortality rate for individual families was $66.2 \%, 83.3 \%$, $76.5 \%, 66.1 \%, 71.6 \%$, and $71.1 \%$ for families $1,2,3,5,6$, and 7, respectively. Resistance to disease was assessed as a binary trait (died or survived until termination of the challenge trials) [24].

\subsection{Sequence polymorphism analysis of exon 2 of the MHC II B gene}

Three hundred and two sequences from 30 resistant turbot (survivor individuals) and 30 susceptible fish (dead individuals) were analyzed. The length of the amplified fragment was either 364,383 or 402 bp. Based on sequence alignment with the turbot MHC II B cDNA complete sequence [13], and the intron-exon boundary GT-AG paradigm, the expected fragment contained part of exon 1 ( 32 bp) and the complete intron 1 region $(68,87$ or $106 \mathrm{bp}$, containing zero, one or two copies of a 19 bp repeat loci, gatcaatacactgagcact). The complete exon 2 region was contained on a 294 bp fragment, which was used for further analysis. Analysis of the exon 2 fragment revealed 37 different amino acid sequences, which represented 37 alleles. Of these 37 alleles, 25 were novel and were deposited in GenBank (Table 2) (GenBank accession No. HQ698599HQ698623).

No insertion/deletion, stop, or frame-shift mutations were found in the $294 \mathrm{bp}$ sequences. Among the 294 nucleotides, $132(44.9 \%)$ sites were polymorphic, and 54 (18.4\%) parsimony informative sites were examined. Alignments showed a high degree of similarity between the 37 sequences $(93.9 \%)$, with a maximum of five different amino acids at each variable codon. Sixty-three (64.3\%) out of the 98 amino acids were variable. The average number of nucleotide differences $(k)$ was 24.7 , and the nucleotide diversity $(\mathrm{Pi})$ and the theta value per site (Theta-W) were 0.084 and 0.107 , respectively. Figure 1 shows the spatial distribution of nucleotide variability. The lowest $\mathrm{Pi}$ value is presented in the middle, while two peaks were found in the upstream and downstream regions of exon 2.

The putative $\mathrm{PBR}$ and non-PBR amino acids in turbot were identified based on the human Class II molecule described by Brown et al. [41]. The values of nonsynonymous $\left(d_{\mathrm{N}}\right)$ and synonymous $\left(d_{\mathrm{S}}\right)$ substitution rates in the PBR were higher than those in the non-PBR (Table 2). These values were assessed using the $8,9,7,9,6,10$, and 38 sequences for families 1, 2, 3, 5, 6, 7 and whole families, respectively. 
Table 2 Novel alleles and GenBank accession number

\begin{tabular}{|c|c|c|c|c|c|}
\hline Allele & GenBank accession No. & Allele & GenBank accession No. & Allele & GenBank accession No. \\
\hline Scma-DAB*0101 & HQ698599 & Scma-DAB*0801 & HQ698606 & Scma-DAB*1203 & HQ698616 \\
\hline Scma-DAB*0102 & HQ698614 & Scma-DAB*0901 & HQ698607 & Scma-DAB*1204 & HQ698623 \\
\hline Scma-DAB*0103 & HQ698619 & Scma-DAB*1001 & HQ698608 & Scma-DAB*1205 & HQ698622 \\
\hline Scma-DAB*0201 & HQ698600 & Scma-DAB*1101 & HQ698609 & Scma-DAB*1301 & HQ698612 \\
\hline$S C M A-D A B * 0301$ & HQ698601 & Scma-DAB*1102 & HQ698615 & Scma-DAB*1401 & HQ698613 \\
\hline Scma-DAB*0401 & HQ698602 & Scma-DAB*1103 & HQ698618 & Scma-DAB*1402 & HQ698620 \\
\hline Scma-DAB*0501 & HQ698603 & Scma-DAB*1201 & HQ698610 & Scma-DAB*1501 & HQ698617 \\
\hline Scma-DAB*0601 & HQ698604 & Scma-DAB*1202 & HQ698611 & Scma-DAB*1601 & HQ698621 \\
\hline Scma-DAB*0701 & HQ698605 & & & & \\
\hline
\end{tabular}

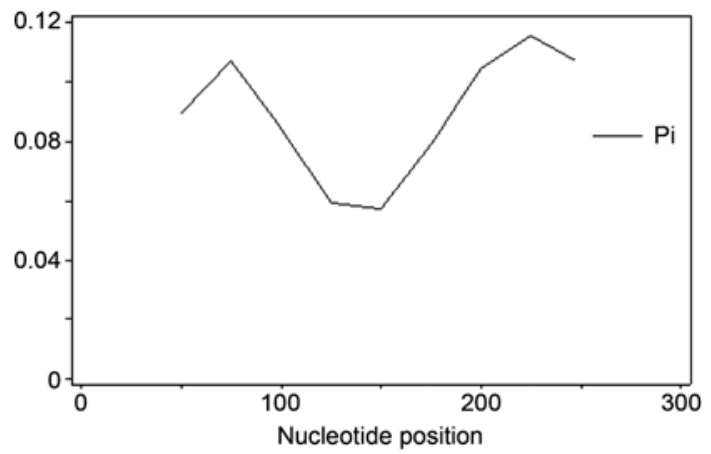

Figure 1 Nucleotide variability within exon 2 of the turbot MHC II B gene in the 37 alleles denoted by Pi (p). Sliding window length: 100; step size: 10 .
The values of $d_{\mathrm{N}}$ in PBR were significantly higher than those of $d_{\mathrm{N}}$ in non-PBR, while values of $d_{\mathrm{S}}$ in PBR were marginally higher than those of $d_{\mathrm{S}}$ in non-PBR. Rates of $d_{\mathrm{N}} / d_{\mathrm{S}}$ in PBR were higher than those of $d_{\mathrm{N}} / d_{\mathrm{S}}$ in non-PBR in families 1, 2, 3, 5 and whole families, but the $d_{\mathrm{N}} / d_{\mathrm{S}}$ rates in PBR were lower than those of $d_{\mathrm{N}} / d_{\mathrm{S}}$ in non-PBR in families 6 and 7 (Table 3).

\subsection{Association between MHC II B alleles and disease resistance/susceptibility to $E$. tarda}

Table 4 shows the number of alleles in each fish and its corresponding individual number. All individuals in this

Table 3 Synonymous $\left(d_{\mathrm{S}}\right)$ and non-synonymous $\left(d_{\mathrm{N}}\right)$ substitution rates in the putative peptide binding region (PBR) and non-peptide binding region (non-PBR) in turbot families

\begin{tabular}{|c|c|c|c|c|c|}
\hline Family & Region & No. of codons & $d_{\mathrm{N}}(\mathrm{SE})$ & $d_{\mathrm{S}}(\mathrm{SE})$ & $d_{\mathrm{N}} / d_{\mathrm{S}}$ \\
\hline \multirow[t]{2}{*}{ Family 1} & PBR & 23 & $0.128 \pm 0.038$ & $0.031 \pm 0.026$ & 4.13 \\
\hline & Non-PBR & 75 & $0.056 \pm 0.014$ & $0.030 \pm 0.015$ & 1.87 \\
\hline \multirow[t]{3}{*}{ Family 2} & PBR & 23 & $0.110 \pm 0.037$ & $0.022 \pm 0.016$ & 5.00 \\
\hline & Non-PBR & 75 & $0.051 \pm 0.016$ & $0.022 \pm 0.013$ & 2.32 \\
\hline & Total & 98 & $0.065 \pm 0.014$ & $0.022 \pm 0.010$ & 2.96 \\
\hline \multirow[t]{3}{*}{ Family 3} & PBR & 23 & $0.188 \pm 0.036$ & $0.096 \pm 0.044$ & 1.96 \\
\hline & Non-PBR & 75 & $0.091 \pm 0.015$ & $0.053 \pm 0.014$ & 1.72 \\
\hline & Total & 98 & $0.114 \pm 0.015$ & $0.064 \pm 0.016$ & 1.78 \\
\hline \multirow[t]{3}{*}{ Family 5} & PBR & 23 & $0.155 \pm 0.047$ & $0.037 \pm 0.031$ & 4.19 \\
\hline & Non-PBR & 75 & $0.054 \pm 0.016$ & $0.025 \pm 0.013$ & 2.16 \\
\hline & Total & 98 & $0.078 \pm 0.017$ & $0.028 \pm 0.013$ & 2.79 \\
\hline \multirow{2}{*}{ Family 6} & Non-PBR & 75 & $0.046 \pm 0.014$ & $0.010 \pm 0.011$ & 4.60 \\
\hline & Total & 98 & $0.058 \pm 0.014$ & $0.016 \pm 0.011$ & 3.63 \\
\hline \multirow[t]{3}{*}{ Family 7} & PBR & 23 & $0.107 \pm 0.033$ & $0.047 \pm 0.026$ & 2.28 \\
\hline & Non-PBR & 75 & $0.051 \pm 0.011$ & $0.022 \pm 0.010$ & 2.32 \\
\hline & Total & 98 & $0.064 \pm 0.011$ & $0.028 \pm 0.010$ & 2.29 \\
\hline \multirow[t]{3}{*}{ Whole } & PBR & 23 & $0.154 \pm 0.038$ & $0.067 \pm 0.032$ & 2.30 \\
\hline & Non-PBR & 75 & $0.079 \pm 0.016$ & $0.050 \pm 0.013$ & 1.58 \\
\hline & Total & 98 & $0.095 \pm 0.015$ & $0.054 \pm 0.013$ & 1.76 \\
\hline
\end{tabular}


Table 4 The number of Scma-DAB alleles in each fish per family and its corresponding individual number

\begin{tabular}{lccccc}
\hline Family & 1 allele & 2 alleles & 3 alleles & 4 alleles & 5 alleles \\
\hline Family1 & 6 & 1 & 2 & & 1 \\
Family 2 & 3 & 4 & 3 & & \\
Family 3 & 2 & 7 & 1 & & \\
Family 5 & 5 & 3 & 1 & 1 & \\
Family 6 & 4 & 3 & 3 & & \\
Family 7 & & 4 & 4 & 1 & 1 \\
Total & 20 & 22 & 14 & 2 & 2 \\
\hline
\end{tabular}

study had between one and five alleles. Approximately five clones from each individual were sequenced, which suggests that turbot have at least three MHC II B loci or copies. All families included both homozygous and heterozygous individuals at exon 2 of the MHC Class II gene, except family 7 which contained only heterozygotes.

Thirty-seven MHC II exon 2 alleles were identified in the 60 fish samples. Several alleles were present in low frequencies and were excluded from allele association analysis between survivor and non-survivor individuals in each family and in whole families. Nine alleles were selected for association analysis (Table 5). Varied distribution frequen cies of alleles in survivors and non-survivors from each family were observed. For example, the Scma-DBBI*02 allele was significantly more frequent in survivors than in non-survivors from whole families $(P<0.01)$, while the frequency of the same allele was marginally greater in survivors than in non-survivors from family 3 . This allele was present only in survivors from family 2 . The Scma-DBB1*10 allele was significantly more frequent in non-survivors than in survivors from whole families $(P=0.02)$. The frequencies of some alleles were not significantly different between survivors and non-survivors from whole families or from each family, including the $S c m a-D B B 1 * 16$ allele $(P=0.999$, $0.0001,0.24,0.09)$ in families $1,5,7$, and pool respectively, and the Scma-DBBI*09 allele $(P=0.0001,0.999,0.12)$ in families 2, 6 and pool. We therefore deduced that the Scma$D B B 1 * 02$ allele was highly associated with resistance to $E$. tarda in turbot, while the $S c m a-D B B 1 * 10$ allele was associated with susceptibility to $E$. tarda.

\section{Discussion}

Most of the previous research into MHC genes in fish species has been focused on the extent of polymorphism within loci $[13,17,42-48]$, as well as association between alleles and resistance/susceptibility to pathogens [15,30,49-52]. In this paper, polymorphisms within the turbot MHC Class II B exon 2 gene in six families, and associations between MHC alleles and resistance/susceptibility to E. tarda, were examined.
This study identified 37 turbot MHC Class II B exon 2 alleles in 60 individuals, of which 25 were novel, while the remaining 12 alleles $(S c m a-D B B 1 * 08, S c m a-D B B 1 * 13$, Scma-DBB1*16, Scma-DBB1*04, Scma-DBB1*14, ScmaDBB1*02, Scma-DBB1*09, Scma-DBB3*02, Scma-DBB1*22, Scma-DBB1*10, Scma-DBB1*07, Scma-DBB3*05. GenBank accession Nos. EF555735, EF555740, EF555743, EF555731, EF555741, EF555729, EF555736, EF555770, EF555749, EF555737, EF555734, EF555773) had been identified in previous studies $[13,30]$. The six turbot families (1-6) examined in this study contained 8, 9, 7, 9, 6, and 10 alleles respectively. The alleles were also unique to each family. A previous study in flounder identified 76 alleles in 60 individuals [15], while another study in water vole found five alleles in 100 individuals [46]. Therefore, the allelic diversity of turbot demonstrated in this study is consistent with other species.

One of the experimental aims was to identify MHC Class II B genes in turbot that were associated with resistance to $E$. tarda, which has a devastating economic impact on turbot farming. Using survival rates based on a preliminary bacterial infection test, we screened for any correlation between MHC allele and resistance to E. tarda in turbot. We determined that allele frequency differed between survivor and non-survivor individuals from different families. Many alleles were present at a very low frequency and therefore had no value for distribution analyses; only nine alleles were used for association analyses (Table 5). The distribution frequency of the Scma-DBBI*02 allele was $27.5 \%$ in survivors in family 2 , but the allele was not present at all in non-survivors $(P=0.0001)$. The distribution frequency of the same allele was $13.7 \%$ and $3.9 \%$ in survivors and non-survivors respectively from family $3(P=0.081)$, while the distribution frequency of $S c m a-D B B 1 * 02$ was $6.2 \%$ and $0.6 \%$ in survivors and non-survivors respectively in whole families $(P=0.0001)$. It is therefore likely that the Scma-DBBI*02 allele is associated with resistance to E. tarda in turbot. The frequency of the $S c m a-D B B 1 * 10$ allele was $15.7 \%$ and $0 \%$ in non-survivors and survivors from family 2 , respectively, while this allele was present at a frequency of $20 \%$ and $16 \%$ in non-survivors and survivors respectively from family 6. The frequency of the same Scma-DBBI*10 allele was $5.9 \%$ and $2.4 \%$ in non-survivors and survivors in whole families, respectively. We inferred that the Scma-DBBI*10 allele might associate with susceptibility to $E$. tarda in turbot (Table 5). In a previous study, Xu et al. [30] discovered that the Scma-DBB1*10 and Scma-DBB1*04 alleles were associated with susceptibility to $E$. tarda in turbot, while Scma-DBB2*01 was associated with resistance to $E$. tarda. As two studies have now associated the Scma-DBBI*10 allele with E. tar$d a$ susceptibility, the MHC Class II B exon 2 has been confirmed as a useful gene marker. In this study, we could not find an association between the Scma-DBB2*01 allele and resistance to $E$. tarda in turbot. This may be a result of using different populations with different genetic backgrounds. 
Table 5 The allele frequency $(>13.7 \%)$ in survivors and non-survivors in six families ${ }^{\text {a) }}$

\begin{tabular}{|c|c|c|c|c|c|c|c|c|c|}
\hline Allele & Mode & Number & Frequency & Family & Allele & Mode & Number & Frequency & Family \\
\hline \multirow[t]{3}{*}{ Scma-DBB1*07 } & $\mathrm{S}$ & 14 & 0.28 & \multirow[t]{3}{*}{ Family 1} & \multirow[t]{3}{*}{ Scma-DBB1*16 } & $S$ & 10 & 0.2 & \multirow[t]{3}{*}{ Family 1} \\
\hline & NS & 8 & 0.16 & & & NS & 10 & 0.2 & \\
\hline & Total & 22 & 0.44 & & & Total & 20 & 0.4 & \\
\hline \multirow[t]{3}{*}{ Scma-DBB $1 * 02$} & $\mathrm{~S}$ & 14 & $0.275 * *$ & \multirow[t]{3}{*}{ Family 2} & \multirow[t]{3}{*}{ Scma-DBB1*09 } & S & 6 & 0.118 & \multirow[t]{3}{*}{ Family 2} \\
\hline & NS & & & & & NS & 5 & 0.098 & \\
\hline & Total & 14 & 0.275 & & & Total & 11 & 0.217 & \\
\hline \multirow{2}{*}{ Scma-DBB3*10 } & NS & & & \multirow{2}{*}{ Family 2} & \multirow{2}{*}{ Scma-DBB $1 * 10$} & NS & 8 & $0.157 * *$ & \multirow{2}{*}{ Family 2} \\
\hline & Total & 8 & 0.157 & & & Total & 8 & 0.157 & \\
\hline \multirow[t]{3}{*}{ Scma-DBB1*16 } & $\mathrm{S}$ & 12 & 0.235 & \multirow[t]{3}{*}{ Family 3} & \multirow[t]{3}{*}{ Scma-DBB $1 * 02$} & $S$ & 7 & 0.137 & \multirow[t]{3}{*}{ Family 3} \\
\hline & NS & 7 & 0.137 & & & NS & 2 & 0.039 & \\
\hline & Total & 19 & 0.373 & & & Total & 9 & 0.176 & \\
\hline \multirow[t]{2}{*}{ Scma-DBB1*04 } & $\mathrm{S}$ & 10 & 0.2 & \multirow[t]{2}{*}{ Family 5} & \multirow[t]{2}{*}{ Scma-DBB $1 * 16$} & $S$ & 10 & 0.2 & \multirow[t]{2}{*}{ Family 5} \\
\hline & NS & 17 & 0.34 & & & NS & & & \\
\hline \multirow[t]{3}{*}{ Scma-DBB3 $* 10$} & $\mathrm{~S}$ & 10 & 0.2 & \multirow[t]{3}{*}{ Family 6} & \multirow[t]{3}{*}{ Scma-DBB $1 * 10$} & $S$ & 8 & 0.16 & \multirow[t]{3}{*}{ Family 6} \\
\hline & NS & 10 & 0.2 & & & NS & 10 & 0.2 & \\
\hline & Total & 20 & 0.4 & & & Total & 18 & 0.36 & \\
\hline Scma-DBB1*14 & $\mathrm{S}$ & 6 & $0.12 * *$ & Family 6 & Scma-DBB1*09 & $S$ & 7 & 0.137 & Family 7 \\
\hline & NS & 1 & 0.02 & & & NS & 9 & 0.177 & \\
\hline & Total & 7 & 0.14 & & & Total & 16 & 0.314 & \\
\hline Scma-DBB $1 * 07$ & $\mathrm{~S}$ & 9 & 0.176 & Family 7 & Scma-DBB $1 * 16$ & $S$ & 2 & 0.039 & Family 7 \\
\hline & NS & 5 & 0.098 & & & NS & 5 & 0.098 & \\
\hline & Total & 14 & $0 . .275$ & & & Total & 7 & 0.137 & \\
\hline Scma-DBB1*07 & $\mathrm{S}$ & 23 & 0.068 & Whole & Scma-DBB $1 * 10$ & S & 8 & 0.024 & Whole \\
\hline & NS & 13 & 0.039 & & & NS & 20 & $0.059 *$ & \\
\hline & Total & 36 & & & & Total & 28 & & \\
\hline Scma-DBB $1 * 16$ & $\mathrm{~S}$ & 35 & 0.104 & Whole & Scma-DBB1*09 & $\mathrm{S}$ & 32 & 0.095 & Whole \\
\hline Scma-DBB1 104 & $\mathrm{~S}$ & 15 & 0.045 & Whole & Scma-DBB3*10 & $\mathrm{S}$ & 16 & 0.047 & Whole \\
\hline & NS & 25 & 0.074 & & & NS & 22 & 0.065 & \\
\hline & Total & 40 & & & & Total & 38 & & \\
\hline Scma-DBB1*14 & $\mathrm{S}$ & 6 & 0.018 & Whole & Scma-DBB1*08 & $S$ & 4 & 0.012 & Whole \\
\hline & NS & 6 & 0.018 & & & NS & 9 & 0.027 & \\
\hline & Total & 12 & & & & Total & 13 & & \\
\hline Scma-DBB $1 * 02$ & $\mathrm{~S}$ & 21 & $0.062 * *$ & Whole & & & & & \\
\hline & NS & 2 & 0.006 & & & & & & \\
\hline & Total & 22 & & & & & & & \\
\hline
\end{tabular}

a) S denotes survivor individual and NS denotes non-survivor individual during the challenge tests. $*$ denotes significant difference at $0.05(P<0.05), * *$ denotes significant difference at $0.01(P<0.01)$.

Other studies have shown associations between MHC alleles and disease resistance in salmonids [25,43,53-55], turbot $[13,30]$, Japanese flounder [14,15], and whitefish [56]. It remains difficult to screen a single allele which is present in survivors or non-survivors from each family, possibly because of environmental factors or because of other genes that are in linkage disequilibrium and that are associated with resistance or susceptibility to $E$. tarda in turbot $[30,55]$.

The rate of non-synonymous $\left(d_{\mathrm{N}}\right)$ to synonymous $\left(d_{\mathrm{S}}\right)$ substitutions is often used for the assessment of balancing selection [57]. Some studies have reported higher nonsynonymous mutations in the PBR of MHC genes $[3,7,13$, 58-60]. In this study, the rate of $d_{\mathrm{N}} / d_{\mathrm{S}}$ in PBR was higher than that of $d_{\mathrm{N}} / d_{\mathrm{S}}$ in non-PBR in families $1,2,3,5$ and whole families, which is consistent with results in other fish species [14,53,60,61]. This finding suggests that positive selection is acting on the PBR of exon 2 of turbot MHC II B genes. However, there were two exceptions in this study, in families 6 and 7 , where $d_{\mathrm{N}} / d_{\mathrm{S}}$ in the PBR was lower than that of in the non-PBR, which has also been observed in other fish species $[14,53]$. It is possible that the PBRs in fish do not exactly correspond to those in humans [14,49], or that the structure of the PBRs is different between MHC Class II B exon 2 alleles at the same locus [62]. Further studies are needed to understand the actual functions of MHC genes. 
In conclusion, exon 2 of the MHC Class II B gene in turbot is polymorphic, and the $S c m a-D B B 1 * 02$ allele is associated with resistance to $E$. tarda, while Scma-DBBI*10 is associated with susceptibility to $E$. tarda in turbot. These markers might be helpful in a selective breeding program for improved bacterial survivability.

This work was supported by the National Key Basic Research Program of China (2010CB126303) and the Tai Shan Scholar Project of Shandong Province, China.

1 Klein J. Natural History of the Major Histocompatibility Complex. New York: John Wiley, 1986

2 Rothbard J B, Gefter M L. Interactions between immunogenetic peptides and Mhc proteins. Annu Rev Immunol, 1991, 9: 527-565

3 Bernatchez L, Landry C. MHC studies in nonmodel vertebrates: What have we learned about natural selection in 15 years? J Evol Biol, 2003, 16: 363-377

4 Hashimoto K, Nakanishi T, Kurosawa Y. Isolation of carp genes encoding major histocompatibility complex antigens. Proc Natl Acad Sci USA, 1990, 87: 6863-6867

5 Juul-Madsen H R, Glamann J, Madsen H O, et al. MHC class II betachain expression in the rainbow trout. Stand J Immunol, 1992, 35: 687-694

6 Hordvik I, Grimholt U, Fosse V M, et al. Cloning and sequence analysis of cDNAs encoding the MHC class II $\beta$ chain in Atlantic salmon (Salmo salar). Immunogenetics, 1993, 37: 437-441

7 Ono H, Klein D, Vincek V, et al. Major histocompatibility complex class II genes of zebrafish. Proc Natl Acad Sci USA, 1992, 89: 11886-11890

8 Klein D, Ono H, O'hUigin C, et al. Extensive MHC variability in cichlid fishes of Lake Malawi. Nature, 1993, 364: 330-334

9 Ono H, O'hUigin C, Tichy H, et al. Major histocompatibility complex variation in two species of cichlid fishes from Lake Malawi. Mol Biol Evol, 1993, 10: 1060-1072

10 Ono $\mathrm{H}$, O'hUigin $\mathrm{C}$, Vincek $\mathrm{V}$, et al. New $\beta$ chain-encoding MHC class II genes in the carp. Immunogenetics, 1993, 38: 146-149

11 Bartl S, Weissman I L. Isolation and characterization of major histocompatibility complex class IIB genes from the nurse-shark. Proc Natl Acad Sci USA, 1994, 91: 262-266

12 Kasahara M, Vazquez M, Sato K, et al. Evolution of the major histocompatibility complex: Isolation of class II A cDNA clones from the cartilaginous fish. Proc Natl Acad Sci USA, 1992, 89: 6688-6692

13 Zhang Y X, Chen S L. Molecular identification, polymorphism, and expression analysis of major histocompatibility complex Class II A and B genes of turbot (Scophthalmus maximus). Mar Biotechnol, 2006, 8: 611-623

14 Zhang Y X, Chen S L, Liu Y G, et al. Major histocompatibility complex IIB allele polymorphism and its association with resistance/ susceptibility to Vibrio anguillarum in Japanese Flounder (Paralichthys olivaceus). Mar Biotechnol, 2006, 8: 600-610

$15 \mathrm{Xu} \mathrm{T} \mathrm{J}$, Chen S L, Ji X S, et al. MHC polymorphism and disease resistance to Vibrio anguillarum in 12 selective Japanese flounder (Paralichthys olivaceus) families. Fish Shellfish Immunol, 2008, 25: 213-221

16 Chen S L, Zhang Y X, Xu M Y, et al. Molecular polymorphism and expression analysis of MHC II B gene from red sea bream (Chrysophrys major). Dev Comp Immunol, 2006, 30: 407-418

17 Xu T J , Chen S L, Ji X S, et al. Molecular cloning, genomic structure, polymorphism and expression analysis of major histocompatibility complex class IIA and IIB genes of half-smooth tongue sole (Cynoglossus semilaevis). Fish Shellfish Immunol, 2009, 27: 192-201

18 Bingulac-Popovic J, Figueroa F, Sato A, et al. Mapping of mhe class $\mathrm{I}$ and class II regions to different linkage groups in the zebrafish, Danio rerio. Immunogenetics, 1997, 146: 129-134
19 Hansen J D, Strassburger P, Thorgaard G H, et al. Expression, linkage, and polymorphism of MHC-related genes in rainbow trout, Oncorhynchus mykiss. J Immunol, 1999, 163: 774-786

20 Michalova V, Murray B W, Sultmann H, et al. A contig map of the MHC class I genomic region in the zebrafish reveals ancient synteny. J Immunol, 2000, 164: 5296-5305

21 Naruse K, Fukamachi S, Mitani H, et al. A detailed linkage map of medaka, Oryzias latipes: Comparative genomics and genome evolution. Genetics, 2000,154: 1773-1784

22 Sambrook J G, Russell R, Umrania Y, et al. Fugu orthologues of human major histocompatibility complex genes: A genome survey. Immunogenetics, 2002, 54: 367-380

23 Phillips R B, Zimmerman A, Noakes M A, et al. Physical and genetic mapping of the rainbow trout major histocompatibility regions: Evidence for duplication of the class I region. Immunogenetics, 2003, 55: 561-569

24 Johnson N A, Vallejo R L, Silverstein J T, et al. Suggestive association of major histocompatibility IB genetic markers with resistance to bacterial cold waterdisease in rainbow trout (Oncorhynchus mykiss). Mar Biotechnol, 2008, 10: 429-437

25 Grimholt U, Larsen S, Nordmo R, et al. MHC polymorphism and disease resistance in Atlantic salmon (Salmo salar), facing pathogens with singl expressed major histocompatibility class I and class II loci. Immunogenetics, 2003, 55: 210-219

26 Srisapoome P, Ohira T, Hirono I, et al. Cloning, characterization and expression of cDNA containing major histocompatibility complex class I, IIa and IIb genes of Japanese flounder Paralichthys olivaceus. Fish Sci, 2004, 70: 264-276

27 Wegner K M, Kalbe G, Raunch J, et al. Genetic variation in MHC class II expression and interactions with $\mathrm{MHC}$ sequence polymorphism in three-spined sticklebacks. Mol Ecol, 2006, 15: 1153-1164

28 Parham P, Ohta T. Population biology of antigen presentation by MHC class I molecules. Science, 1996, 272: 67-74

29 Philip W. Hedrick Balancing selection and MHC. Genetica, 1999, 104: $207-214$

30 Xu J Y, Chen S L, Ding H. Specific MHC class II B alleles associated with resistance to Edwardsiella tarda in turbot, Psetta maxima (L.). J Fish Dis, 2009, 32: 637-640

31 Li Y, Yan X H, Chen J X, et al. Studies on the characteristics of pathogenic Edwardsiella tarda isolated from diseased Scophthalmus maximus. J Ocean Univ China, 2006, 36: 649-654

32 Henryon M, Berg P, Olesen N J, et al. Selective breeding provides an approach to increase resistance of rainbow trout (Onchorhynchus mykiss) to the diseases, enteric red mouth disease, rainbow trout fry syndrome, and viral haemorrhagic septicaemia. Aquaculture, 2005, 250: 621-636

33 Chen S L, Du M. Development and characterization for growth rate and disease resistance of families in half-smooth tongue sole (Cynoglossus semilaevis). J Fish China, 2010, 34: 1789-1794

34 Sambrook J, Fritsch E F, Maniatis T. Molecular Cloning: A Laboratory Manual. 2nd ed. Cold Spring Harbor: Cold Spring Harbor Laboratory Press, 1989

35 Thompson J D, Higgins D G, Gibson T J. Clustal W: Improving the sensitivity of progressive multiple sequence alignment through sequence weighting, positions-specific gap penalties and weight matrix choice. Nucleic Acid Res, 1994, 22: 4673-4680

36 Tamura K, Dudley J, Nei M, et al. MEGA4: Molecular evolutionary genetics analysis (MEGA) software version 4.0. Mol Biol Evol, 2007, 24: $1596-1599$

37 Nei M, Gojobori T. Simple methods for estimating the numbers of synonymous and nonsynonymous nucleotide substitutions. Mol Biol Evol, 1986, 3: 418-426

38 Librado P, Rozas J. DnaSP v5: A software for comprehensive analysis of DNA polymorphism data. Bioinformatics, 2009, 25: 1451-1452

39 Davies C J, Andersson L, Ellis S A, et al. Nomenclature for factors of the BoLA system, report of the ISAG BoLA Nomenclature Committee. Anim Genet, 1997, 28: 159-168

40 Xu R F, Li K, Chen G H, et al. Genetic variation within exon 2 of the MHC B-LB II gene inTibetan chicken. Acta Genet Sin, 2005, 32: 
1136-1146

41 Brown J H, Jardetzky T S, Gorga J C, et al. Three-dimensional structure of the human class II histocompatibility antigen HLA-DR1. Nature, 1993, 364: 33-39

42 Axtner J, Sommer S. Gene duplication, allelic diversity, selection processes and adaptive value of MHC class II DRB genes of the bank vole, Clethrionomys glareolus. Immunogenetics, 2007, 59: 417-426

43 Rakus K L, Wiegertjes G F, Stet R J M, et al. Polymorphism of MHC class II B genes in different lines of the common carp Cyprinus carpio L. Aquat Living Resour, 2003, 16: 432-437

44 Graser R, O'huigin C, Vincek V, et al. Trans-species polymorphism of class II Mhc loci in danio fishes. Immnunogenetics, 1996, 44, 36-48

45 Oliver M K, Piertney S B. Isolation and characterization of a MHC class II DRB locus in the European water vole Arvicola terrestris. Immunogenetics, 2006, 58: 390-395

46 Meyer L Y, Sommer S. MHC diversity and the association to nematode parasitismin the yellow-neckedmouse Apodemus flavicollis. Mol Ecol, 2005, 14: 2233-2243

47 Harf R, Sommer S. Association between major histocompatibility complex class II DRB alleles and parasite load in the hairyfooted gerbil, Gerbillurus paeba, in the Southern Kalahari. Mol Ecol, 2005, 14: 85-91

48 Ottová E, Simkova A, Martin J F, et al. Evolution and transspecies polymorphism of MHC class IIb genes in cyprinid fish. Fish Shellfish Immunol, 2005, 18: 199-222

49 Kjøglum S, Larsen S, Grimholt U, et al. How specific MHC class I and class II combinations affect disease resistance against infectious salmon anaemia in Atlantic salmon (Salmo salar). Fish Shellfish Immunol, 2006, 21: 431-441

50 Wynne J W, Cook M T, Nowak B F, et al. Major histocompatibility polymorphism associated with resistance towards amoebic gill disease in Atlantic salmon (Salmo salar L.). Fish Shellfish Immunol, 2007, 22: 707-717

51 Glover K A, Grimholt U, Bakke H G, et al. Major histocompatibility complex (MHC) variation and susceptibility to the sea louse Lepeophtheirus salmonis in Atlantic salmon Salmo salar. Dis Aquat Organ,
2007, 76: 57-65

52 Miller K M, Winton J R, Schulze A D, et al. Major histocompatibility complex loci are associated with susceptibility of Atlantic salmon to infectious hematopoietic necrosis virus. Environ Biol Fishes, 2004, 69: $307-316$

53 Langefors A, Lohm J, Grahn M, et al. Association between major histocompatibility complex class IIB alleles and resistance to Aeromonas salmonicida in Atlantic salmon. Proc R Soc Lond, 2001, 268: 479-485

54 Ozaki A, Sakamoto T, Khoo S-K, et al. Quantitative trait loci (QTLs) associated with resistance/susceptibility to infectious pancreatic necrosis virus (IPNV) in rainbow trout (Oncorhynchus mykiss). Mol Genet Genom, 2001, 265: 23-31

55 Palti Y, Nichols K M, Waller K I, et al. Association between DNA polymorphisms tightly linked to MHC class II genes and IHN virus resistance in backcrosses of rainbow and cutthroat trout. Aquaculture, 2001, 194: 283-289

56 Wedekind C, Walker M, Portmann J, et al. MHC-linked susceptibility to a bacterial infection, but no MHC-linked cryptic female choice in whitefish. J Evol Biol, 2004, 17: 11-18

57 Hughes A L, Nei M. Nucleotide substitution at major histocompatibility complex class II loci: Evidence for overdominant selection. Proc Natl Acad Sci USA, 1989, 86: 958-962

58 Garrigan D, Hedrick P W. Perspective: Detecting adaptive molecular polymorphism: Lessons from the MHC. Evolution, 2003, 57: 1707-1722

59 Sommer S. The importance of immune gene variability (MHC) in evolutionary ecology and conservation. Front Zool, 2005, 2: 16

$60 \mathrm{Xu}$ T J, Sun Y N, Wang R X. Gene duplication and evidence for balancing selection acting on MHC class II DAA gene of the halfsmooth tongue sole (Cynoglossus semilaevis). Marine Genomics, 2010, 3: 117-123

61 Kim T J, Parker K M, Hedrick P W. Major histocompatibility complex differentiation in Sacramento River chinook salmon. Genetics, 1999, 151: 1115-1122

62 Scott C A, Peterson P A, Teyton L, et al. Crystal structures of two I-Ad-peptide complexes reveal that high affinity can be achieved without large anchor residues. Immunity, 1998, 8: 319-329

Open Access This article is distributed under the terms of the Creative Commons Attribution License which permits any use, distribution, and reproduction in any medium, provided the original author(s) and source are credited. 